Lymphology 52 (2019) 25-34

\title{
CONSERVATIVE MANAGEMIENT OF CHYLOUS ASCITES AFTER ONCOLOGICAL SURGERY FOR PERIPHERAL NEUROBLASTIC TUMORS IN PEDIATRIC PATIENTS
}

L. Pio, F. Boccardo, S. Avanzini, I. Paraboschi, C. Granata,

A. Garaventa, S. Dessalvi, G. Martucciello, G. Mattioli

DINOGMI (LP,IP,GM,GM), University of Genoa; Pediatric Surgery Unit (LP,SA,IP,GM,GM), Istituto Giannina Gaslini; Unit of Lymphatic Surgery (FB,SD), Department of Surgery, IRCCS S. Martino Hospital - IST, National Cancer Institute for Cancer Research, University of Genoa; Pediatric Radiology Unit (CG), and Pediatric Oncology Unit (AG), Istituto Giannina Gaslini, Genoa, Italy

\section{ABSTRACT}

Chylous ascites may complicate the postoperative course of abdominal surgery mainly due to the iatrogenic disruption of the lymphatic channels during extensive retroperitoneal dissection.

Sparse data are available regarding treatment; however, in many cases a recommended first-line treatment approach is by way of enteral feeding, consisting of a formula high in medium-chain triglycerides (MCTs) together with a complete total parenteral nutrition teamed with somatostatin (or an equivalent). Nonetheless, the ligation of chylous fistulae, together with the application of Fibrin glue, as well as the creation of peritoneal-venous shunts have also been documented. The aims of this study are to document incidence of postoperative chylous ascites following resection of abdominal peripheral neuroblastic tumors, evaluate efficacy of the management of chylous ascites, and investigate the main risk factors. A survey was carried out over a span of six years, from March 2010 to March 2016 at Giannina Gaslini Children's Hospital involving seventy-seven children with resections of peripheral neuroblastic tumors. Incidence rate of postoperative chylous ascites following a normal diet was 9\% ( $n=7)$. Treatment using total parenteral nutrition with octreotide resulted in a complete recovery from chylous ascites within a 20 day period without recurrence. Length of operative time, nephrectomy, and the extension of lymphadenectomy were all significantly associated with a higher incidence of postoperative chylous ascites $(p<0.05)$ which also lengthened hospital stay $(p<0.05)$ and possibly delayed beginning adjuvant chemotherapy.

Keywords: chylous ascites, peripheral neuroblastic tumors, oncological surgery, children, octreotide

Surgery is a milestone in therapeutic strategy for peripheral neuroblastic tumors. However, postoperative complications, such as chylous ascites, may occur (1-4). Accumulation of triglyceride-rich lymphatic fluid in the peritoneal cavity is due to chyle extravasation resulting from lymphatic disruption during surgery. In children, primary chylous ascites is extremely rare and commonly due to lymphat- 
ic congenital anomalies (5-7). Secondary forms are mainly due to intestinal malrotation, intussusception, an incarcerated hernia, lymphangioma, blunt abdominal trauma, malignancy, liver diseases, peritoneal dialysis, abdominal tuberculosis, filariasis, or extensive abdominal surgery (8).

The management of postoperative chylous ascites in children is still undergoing assessment and exploration, although conservative treatment is strongly recommended for many patients. It consists of a medium-chain triglyceride (MCT) diet, total parenteral nutrition (TPN) and pharmacological agents such as somatostatin or octreotide (6,7,9-16).

An enteral nutrition plan with an exclusively MCT diet is reported to be effective since it reduces lymph flow thus allowing spontaneous healing of chylous fistulas. MCTs are in fact directly absorbed into the portal venous system, bypassing the chylomicron transport (12).

TPN reduces mesenteric lymphatic flow and chyle production, restores nutritional deficits, and balances metabolic impairments. Octreotide is a synthetic long-acting somatostatin analogue with multi-organ effect, exacting mechanism of action which is not completely understood. Although it has been successfully used in children since 2001 (16), its use is still limited. While other conservative treatments usually take many weeks to be effective, however, it seems to reduce the recovery time.

Essential surgical treatment is mandatory only in intractable cases refractory to conservative measures. It consists of surgical ligation of the chylous fistulae, application of fibrin glue (17) or the creations of peritoneal-venous shunts $(14,18-32)$.

The aim of the primary direct surgical repair is to identify and close the lymphatic fistula, but anatomic variations and presence of areas of diffuse lymphatic leakage may limit its feasibility. To overcome these limits, when no defined leakage has been identified, some authors $(17,33)$ propose the application of Fibrin glue on absorbable mesh.

Since data are not robust in the literature
$(4,13,34)$, the aims of the present study are to document the incidence of postoperative chylous ascites following surgery for peripheral neuroblastic tumors, evaluate the success of its conservative management, and investigate the main risks factors for its occurrence.

\section{MATERIAL AND METHODS}

Demographic, clinical, and surgical features of all the infants with newly diagnosed peripheral neuroblastic tumors who underwent surgical exploration from March 2010 to March 2016 have been documented.

The need for surgery was indicated by an oncological team which included pediatric oncologists, surgeons, and radiologists. All children underwent tumor resection with retroperitoneal lymphatic dissection when deemed necessary. Informed consent was given as well as the approval of the Institutional Review Board, in accordance with the Helsinki Declaration (2013 revision). Neuroblastoma dissection was accomplished with bipolar dissection. Scalpel dissection technique was carried on in case of vascular encasement with opening of the tumor surrounding the vessels to the tunica media. In cases with lymphatic vessel identification, a selective ligature was provided. A peritoneal drain was systematically placed at the end of all surgical procedures.

TPN was administered postoperatively via a central vein to guarantee daily metabolic requirements. All patients were monitored regarding proteins, electrolytes, liver function, and blood fat. Supportive treatments (such as albumin, diuretics, and antibiotics) were given to patients as required. The diagnosis of chylous ascites was confirmed by analyzing the fluid obtained through peritoneal drainage. A creamy peritoneal fluid with a volume of $>100 \mathrm{ml} /$ day and with a triglyceride concentration $>110 \mathrm{mg} / \mathrm{dl}$ were considered diagnostic. Incidence was calculated and the main suspected risks factors for it occurrence were investigated (4).

The peritoneal cavity drainage tubes inserted during operation were left in situ as 
long as chylous ascites persisted. The quality and the quantity of drainage fluid were monitored daily. In case of occurrence of postoperative chylous ascites, it was decided to adopt a first-line conservative protocol with the use of TNP and introduction of octreotide therapy. Thus, all cases received continuous intravenous infusion of octreotide at a dose of $2 \mathrm{mcg} / \mathrm{kg} / \mathrm{h}$ (Sandostatin, Norvatis Pharma AG) proceed by a single bolus administered in an hour.

Clinical or adverse effects were noted, and once the peritoneal drainage was less than 20 $\mathrm{ml} / \mathrm{day}$, TPN and octreotide doses were gradually reduced along with the recovery of an oral low-fat diet.

Medical records, including day in which postoperative ascites occurred, duration of octreotide therapy, and length of hospital stay were recorded and follow up evaluation was based on the clinical and imaging findings.

\section{RESULTS}

From March 2010 to March 2016, a total of seventy-seven patients (41 female; 36 males) underwent surgery for abdominal neuroblastic tumors consistent with the most recent recommended guidelines.

\section{Patients Who Did Not Develop Chylous Ascites}

Patient records are reported in Table 1. In forty-six patients the neoplastic mass came from the adrenal medulla (19 from the left side; 22 from the right side; in $\mathbf{5}$ cases the laterality was not recorded); in 13 cases from the abdominal paravertebral sympathetic chain ( 8 from the left side; 3 from the right side; 1 bilaterally; in 1 case the laterality was not specified) while five patients from the pelvic sympathetic ganglia. Both thoracic and abdominal involvement was identified in five cases ( 2 from the right side, 3 from the left side) and an abdominopelvic growth was detected in a single case (Fig. 1).

According to the International Neuroblas- toma Staging System (INSS), twenty-two patients were classified as stage $\mathrm{S} 1$, five as stage $2 \mathrm{~A}$, three stage $2 \mathrm{~B}$, fourteen $\mathrm{S} 3$, twenty-two $\mathrm{S} 4$, and seven patients stage 4S. Data were not available in four cases. According to the International Neuroblastoma Risk Group (INRG), 37 patients presented localized disease $(25 \mathrm{~L} 1$; $12 \mathrm{~L} 2)$ and 20 patients suffered from metastatic disease (M 15; Ms 5). However, records were not available for 20 patients.

Thirty-one patients (the average age at the time of surgery was forty-two months: range 1 month - 19 years) were treated with induction chemotherapy since the tumors were initially unresectable while eighteen patients underwent preoperative radiotherapy therapy to the surgical bed. Twenty-four patients underwent laparoscopic resection (one of which using the robotic-assisted technique) while the remaining 46 underwent open surgery.

Gross total resection was achieved in fifty-five patients, near complete tumor resection in fourteen and an incomplete resection in one case. Mean operation time was 240 minutes (range from 50m-630m). Extensive lymphadenectomy greater than or equal to seven lymph nodes was performed on twenty patients. Adrenalectomy was performed on 42 patients while nephrectomy in six cases. Length of hospital stay was 14 days (range 3 81 days).

\section{Patients Who Developed Chylous Ascites}

In seven patients ( 4 male; 3 female) chylous leakage was detected postoperatively (Fig. 2). In five cases the adrenal medullary was involved ( 3 of the left side; 2 of the right side) in one case the abdominal paravertebral sympathetic chain, and in another the thoracoabdominal paravertebral sympathetic chain. All patients were treated with open surgery and gross total resection was achieved in four patients and near complete tumor resection in two cases. In the remaining single case only an incomplete resection was achieved. The average age of surgery was twenty-four months, varying from five months to five 
TABLE 1

Risk Factors of Postoperative Chylous Ascites Following Surgery for Abdominal Peripheral Neuroblastic Tumors

\begin{tabular}{|c|c|c|c|c|}
\hline & $\begin{array}{l}\text { Chylous } \\
\text { ascites } \\
\text { Yes }(n=7)\end{array}$ & $\begin{array}{l}\text { Chylous } \\
\text { ascites } \\
\text { No }(n=70)\end{array}$ & $\begin{array}{l}\text { Total } \\
(n=77)\end{array}$ & P value \\
\hline \multicolumn{5}{|l|}{ Gender } \\
\hline - $\mathrm{F}$ & 3 & 38 & 41 & \multirow[t]{2}{*}{0.70} \\
\hline • $\mathrm{M}$ & 4 & 32 & 36 & \\
\hline \multicolumn{5}{|l|}{ Age at surgery } \\
\hline - Mean & $24 \mathrm{~m}$ & $44 \mathrm{~m}$ & $42 \mathrm{~m}$ & \multirow[t]{2}{*}{0.30} \\
\hline - Range & $5 m-59 m$ & $1 \mathrm{~m}-19 \mathrm{y}$ & $1 \mathrm{~m}-19 \mathrm{y}$ & \\
\hline \multicolumn{5}{|l|}{ ASA status } \\
\hline - ASA1 & 0 & 6 & 6 & \multirow[t]{4}{*}{0.83} \\
\hline - $\quad$ ASA 2 & 5 & 45 & 50 & \\
\hline - $\quad$ ASA 3 & 2 & 17 & 19 & \\
\hline - $\quad$ nd & 0 & 2 & 2 & \\
\hline \multicolumn{5}{|l|}{ Primary site } \\
\hline - Adrenal medullary & 5 & 46 & 51 & \multirow[t]{2}{*}{1.00} \\
\hline - Other than adrenal & 2 & 24 & 26 & \\
\hline \multicolumn{5}{|l|}{ Tumor histology } \\
\hline - Neuroblastoma & 7 & 59 & 66 & \multirow[t]{3}{*}{0.53} \\
\hline - Ganglioneuroblastoma & $\mathbf{0}$ & 8 & 8 & \\
\hline - Ganglioneuroma & 0 & 3 & 3 & \\
\hline \multicolumn{5}{|l|}{ Stage INRG } \\
\hline L1 & 2 & 23 & 25 & \multirow[t]{5}{*}{0.42} \\
\hline - $\quad$ L2 & 0 & 12 & 12 & \\
\hline - $\mathbf{M}$ & 3 & 12 & 15 & \\
\hline - $\quad \mathrm{Ms}$ & $\mathbf{0}$ & 5 & 5 & \\
\hline - nd & 2 & 18 & 20 & \\
\hline \multicolumn{5}{|l|}{ Stage INSS } \\
\hline - S1 & $\mathbf{0}$ & 22 & 22 & \multirow[t]{7}{*}{0.01} \\
\hline - $\quad \mathrm{S} 2 \mathrm{~A}$ & $\mathbf{0}$ & 5 & 5 & \\
\hline - $\quad$ S2B & 2 & 1 & 3 & \\
\hline - $\quad \mathrm{S3}$ & 2 & 12 & 14 & \\
\hline - $\quad \mathrm{S} 4$ & 3 & 19 & 22 & \\
\hline - $\quad$ S4S & 0 & 7 & 7 & \\
\hline - nd & $\mathbf{0}$ & 4 & 4 & \\
\hline \multicolumn{5}{|l|}{ Induction chemotherapy } \\
\hline - $\mathbf{y}$ & 5 & 26 & 31 & \multirow[t]{2}{*}{0.11} \\
\hline - $\mathrm{n}$ & 2 & 44 & 46 & \\
\hline \multicolumn{5}{|l|}{ Neoadjuvant radiotherapy } \\
\hline$\bullet \quad \mathbf{y}$ & 1 & 17 & 18 & \multirow[t]{2}{*}{1.00} \\
\hline - $\mathrm{n}$ & 6 & 53 & 59 & \\
\hline \multicolumn{5}{|l|}{ Surgical approach } \\
\hline - Open & 7 & 44 & 51 & \multirow[t]{2}{*}{0.09} \\
\hline - Laparoscopic & 0 & 26 & 26 & \\
\hline \multicolumn{5}{|l|}{ Resection type } \\
\hline - Gross total resection & 5 & 52 & 57 & \multirow[t]{2}{*}{1.00} \\
\hline - Other & 2 & 18 & 20 & \\
\hline \multicolumn{5}{|l|}{ Blood transfusion } \\
\hline$\bullet \quad \mathrm{y}$ & $\begin{array}{l}4 \\
3\end{array}$ & $\begin{array}{l}22 \\
48\end{array}$ & $\begin{array}{l}26 \\
51\end{array}$ & 0.22 \\
\hline
\end{tabular}




\begin{tabular}{|c|c|c|c|c|}
\hline \multicolumn{5}{|l|}{ Table 1 (continued) } \\
\hline & $\begin{array}{l}\text { Chylous } \\
\text { ascites } \\
\text { Yes }(n=7)\end{array}$ & $\begin{array}{l}\text { Chylous } \\
\text { ascites } \\
\text { No }(n=70)\end{array}$ & $\begin{array}{l}\text { Total } \\
(n=77)\end{array}$ & P value \\
\hline \multicolumn{5}{|l|}{ Nephrectomy } \\
\hline - $y$ & 3 & 3 & 6 & $0.0084 *$ \\
\hline - $\mathrm{n}$ & 4 & 67 & 71 & \\
\hline \multicolumn{5}{|l|}{ Adrenalectomy } \\
\hline - $\mathbf{y}$ & 6 & & 48 & 0.24 \\
\hline - $\mathrm{n}$ & 1 & & 29 & \\
\hline \multicolumn{5}{|c|}{ Extensive lymphadenectomy $(>7)$} \\
\hline - $y$ & 5 & 13 & 20 & $0.0066 *$ \\
\hline - $\mathrm{n}$ & 2 & 57 & 57 & \\
\hline \multicolumn{5}{|l|}{ Operative time } \\
\hline - mean & $240 \mathrm{~m}$ & $403 \mathrm{~m}$ & $240 \mathrm{~m}$ & $0.0097 *$ \\
\hline - $\quad$ range & $50 \mathrm{~m}-630 \mathrm{~m}$ & $310 \mathrm{~m}-630 \mathrm{~m}$ & $\begin{array}{l}50 \mathrm{~m}- \\
630 \mathrm{~m}\end{array}$ & \\
\hline \multicolumn{5}{|l|}{ Length of hospital stay } \\
\hline - mean & 26d & 13d & 14d & $0.0055 *$ \\
\hline - range & $15 d-73 d$ & 3d-81d & 3d-81d & \\
\hline
\end{tabular}

INRG: International Neuroblastoma Risk Groub classification: INSS: International Neuroblastoma

years. Induction chemotherapy was required in four patients, while one patient received preoperative radiotherapy. Extensive lymphadenectomy ( $>7$ lymph nodes) was performed in five patients.

Nephrectomy was required in three patients. Mean surgical time was 403 minutes (range from $310 \mathrm{~m}-630 \mathrm{~m}$ ). Chylous leakage was detected within a mean interval of 7 days (range 3d-29d) after surgery. The mean duration of octreotide infusion therapy was 10 days (range 4d-20d).

No complications were found related to TPN and no side effects of octreotide were recorded. All patients were successfully managed with conservative treatment and none required any further surgery.

The average length of hospital stay was 26 days (range $15-73$ days). Follow-up studies found no recurrence (while following a normal diet). Regarding the main suspected risk factors, the entity of lymphadenectomy and the length of surgery were both associated with higher incidences of postoperative chylous ascites (respectively, $\mathrm{p}=\mathbf{0 . 0 0 6 6}$ and $\mathrm{p}=\mathbf{0 . 0 0 9 7}$ ) using Fisher's exact test. Occurrence complicated the postoperative course by significant- ly lengthening duration of hospitalization $(\mathrm{p}=0.0055)$.

\section{DISCUSSION}

Surgery plays a fundamental rule in the management of abdominal neuroblastic tumors. Surgical exploration is performed to confirm diagnosis, obtain biological characterization, sample loco regional lymph nodes, and attempt to obtain complete resection.

Large retroperitoneal neuroblastomas may infiltrate blood vessels (Fig. 1) leading to massive bleeding during resection. Other than vascular injury, nephrectomy, infections, or organ failure may occur $(2,3)$. In addition, neoplastic growth could infiltrate lymphatic vessels causing rupture in the peritoneal cavity during surgical resection. Chyle leakage is a known complication of abdominal surgery which is still under investigation in pediatric patients. Constant protein and nutrient loss may lead to malnutrition and alter coagulation time. Loss of immunoglobulins and lymphocytes may interfere with immunological functions, while hydro-electrolyte alterations may cause dehydration. 

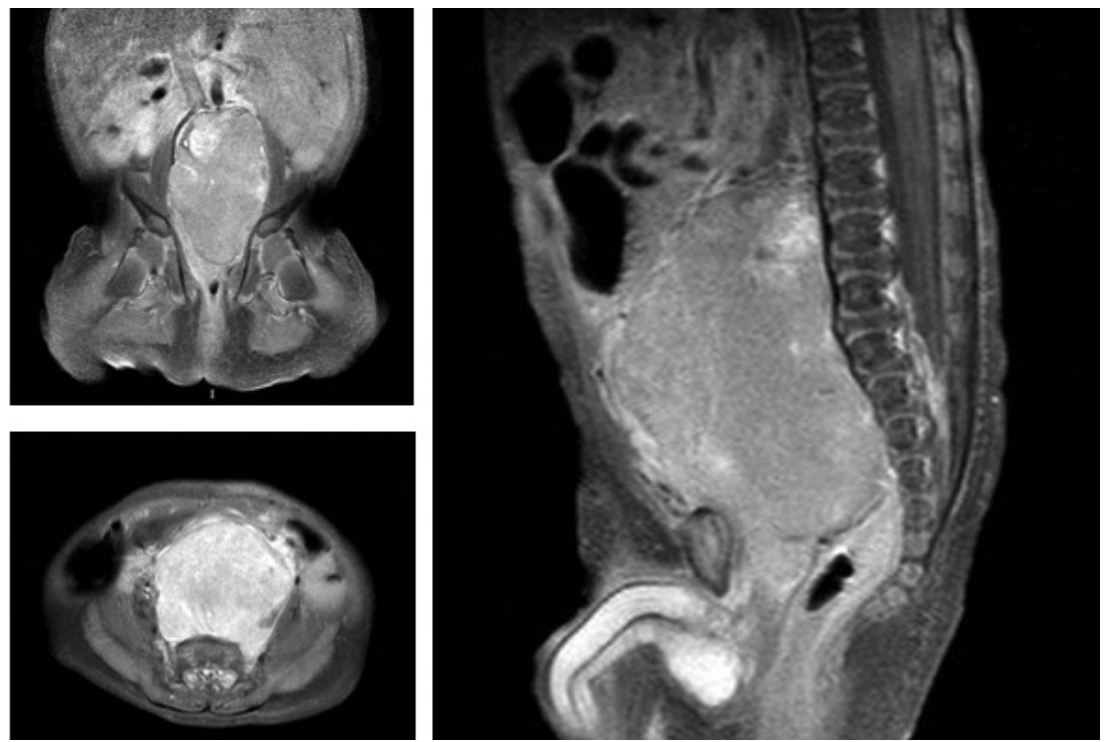

Fig. 1. MRI T1-weighted images after intravenous contrast administration showing a $61 \times 49 \times 41 \mathrm{~mm}$ abdominopelvic mass. It extends caudally in a retroaortic and paracaval position from the blood vessels of the kidney to the ischioanal fossa, displacing the common iliac vessels.
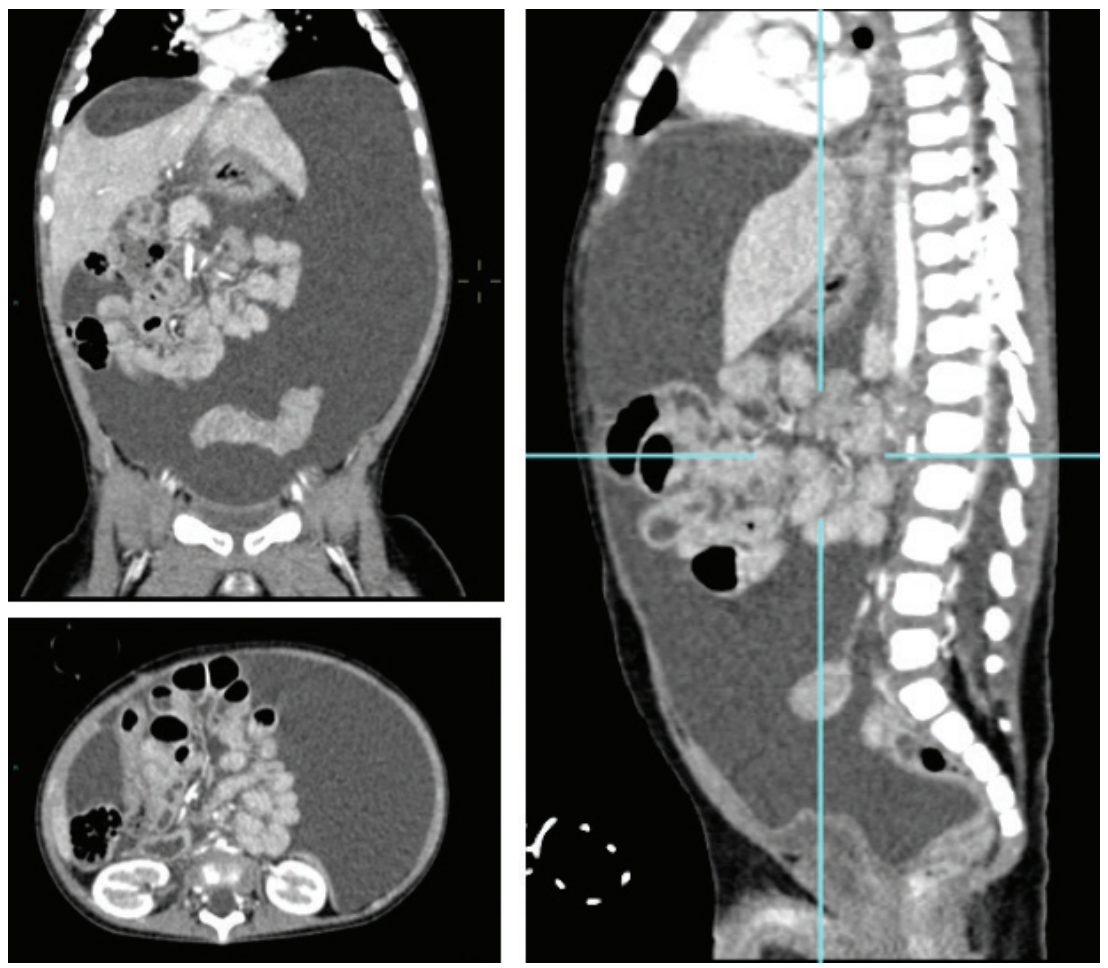

Fig. 2. CT scan images depict massive chylous ascites following radical surgical treatment of abdominal neuroblastoma.

Permission granted for single print for individual use.

Reproduction not permitted without permission of Journal LYMPHOLOGY. 
Although conservative treatment is strongly recommended in most patients, duration of this treatment before surgery is undertaken is controversial. Nevertheless, a period of 4-8 weeks is usually recommended. The use of octreotide in children is still limited and reviews mostly deal only with reports of single cases $(7,9,13,35,36)$.

Octreotide is a synthetic somatostatin analog comprising eight amino acids which, according to recent studies, reduces lymphatic production and flow. It also inhibits secretion of various digestive hormones such as glucagon and insulin, and digestive juices such as gastric acid, pancreatic fluid, and bile, and thereby decreases blood flow to the internal organs which decreases the lymph flow $(37,38)$. It constricts smooth muscle via the somatostatin receptors in the lymph duct endothelium and smooth muscles (39).

In the context of chyle fistula, the efficacy of somatostatin may be a result of its ability to reduce gastric, pancreatic, and intestinal secretions, to inhibit intestinal motor activity, and to slow intestinal absorption, reducing splanchnic blood flow and decreasing hepatic venous pressure $(40,41)$.

Large sample size studies are lacking, and no gold standard treatment has been defined regarding timing and the dosage of octreotide. A prospective study in dogs demonstrated a threefold decrease in thoracic duct flow and decreased ratio of triglycerides after administration of octreotide (42). Similarly, in a study conducted by Ahn et al (43) on postoperative chyle leakage after neck dissection, triglycerides concentrations in the postoperative drainage fluid were consistently lower in the octreotide group than in the in the control group throughout the postoperative period. These results suggested that both the lymph flow and triglycerides concentrations in the major lymphatic channels were attenuated by octreotide injection, supporting the hypothesized effect of octreotide on the lymphatics. Kuboki et al (44) also showed that the decrease of the daily drainage output is significantly earlier in patients treated with octreotide (median 1 vs 6 days).

Leibovitch et al (10) reported that 2 to 6 weeks of TPN are needed for recovery in $60 \%$ to $100 \%$ of cases. Conversely, several studies indicate that the recovery time is much less if somatostatin or its correspondent is used. Yang et al (9) report a shorter curative time without any recurrence in two cases of chylous ascites managed with TPN and octreotide compared to the other two receiving only TPN (median 2 days vs 27 days). Pan et al (12) confirmed that complete clinical success is reached earlier in patients treated with somatostatin compared with patients treated without (median 4 days vs 12 days). In this study, tube removal time, time to resume an oral diet, and the length of hospital stay were all significantly shorter in the somatostatin group.

The high cost of the somatostatin seems to be largely compensated by the decreased recovery time and incidence of complications and by the shorter length of nutrition support and hospital stay (45).

Regarding surgical management of chylous ascites, efficacy of the creation of a peritoneal-venous shunt is controversial; some authors report its success in the treatment of intractable postoperative chylous ascites in children, whereas others note a high failure rate associated with several complications, such as shunt fracture or occlusion, cardiac congestion, disseminated intravascular coagulation, fat emboli, vein thrombosis, infections, sepsis, nephritis, dissemination of malignant cells, or perforation of the coronary sinus (11,18-32,46-47).

Several known risk factors for occurrence of postoperative chylous ascites have been investigated. Kaas et al (11) considered surgeries proceeded by cytoreduction or hyperthermic intraperitoneal chemotherapy, extensive retroperitoneal lymph node dissection, oesophageal, gastric or retroperitoneal resections as high-risk procedure. Evans et al (14) identified a significant incidence of chylous ascites in patients developing significant intraoperative blood loss during retroperitoneal lymph node 
dissection (OR 1.33) or undergoing preoperative chemotherapy (OR 1.24). Baniel et al (15) added the resection of the inferior vena cava as part of the retroperitoneal node dissection for testicular cancer as a high risk procedure. Other known risk factors were adjuvant radiation and induction chemotherapy $(32,45,48)$.

In our series, a total of seventy-seven patients with abdominal peripheral neuroblastic tumors were evaluated during the study period. Seven patients presented chylous ascites after surgery, mainly by the 3rd day of oral nutrition. This incidence rate (9\%) was higher than the $7.4 \%$ reported by Kass et al (11) but lower than the $20 \%$ reported by Qureshi et al (4).

All patients received TPN and octreotide infusion as first-line treatment. None of the reported side effects of octreotide (such as hypertension, malabsorption, diarrhea, fatty stools, nausea, flatulence, liver dysfunction, or hyperglycemia) occurred.

The rate of conservative success was $100 \%$ and no patients required further surgery, even in massive leak (Fig. 1). The chylous ascites diminished and stopped within 20 days in all patients (mean 10 days, range 4d-20d). When the drainage was stopped, all patients were started a low fat or MCT based diet. Gradually a normal diet was introduced.

All patients were discharged within 73 days of surgery (mean 26 days; range 15-73 days). One month later follow-up assessment did not show any recurrence of chyloperitoneum with a normal diet.

Recently, Qureshi et al (4) described that the number of lymph nodes resected was strongly associated with the risk of chyle leaks. In our series, the extent of lymphadenectomy, nephrectomy, and operative time were all associated with a higher incidence of postoperative chylous ascites ( $p$-value $<0.05$ ). Neither chemotherapy nor radiotherapy, undergone before surgery, seemed to correlate with its occurrence. The length of the hospital stay was significantly longer in patients that developed a chyle leak (mean 26 days vs 13 days), as also reported by Qureshi et al (4). It possibly delayed adjuvant chemotherapy to limit the risk of subsequent possible infection.

\section{CONCLUSIONS}

TPN along with octreotide infusion seems to be effective in the treatment of chylous ascites after oncological surgery in children. Drug safety and favorable outcome suggest that the conservative management should be considered as the first therapeutic option. However, further randomized case-control trials are required to compare different conservative approaches, such as TPN alone or associated with octreotide. Assessment of the most appropriate octreotide regimen in terms of duration of treatment and its optimal dosage in infants should also be further investigated.

\section{CONFLICT OF INTEREST AND DISCLOSURE}

The authors declare no competing financial interests exist.

\section{REFERENCES}

1. Cecchetto, G, V Mosseri, B De Bernardi, et al: Surgical risk factors in primary surgery for localized neuroblastoma: The LNESG1 study of the European International Society of Pediatric Oncology Neuroblastoma Group. J. Clin. Oncol. 20 (2005), 8483-8489.

2. Azizkhan, RG, A Shaw, JG Chandler: Surgical complications of neuroblastoma resection. Surgery 97 (1985), 514-517.

3. Asabe, K, Y Oka, H Kai, et al: Thoracoscopic surgery in children in the Kyushu area of Japan. Pediatr. Int. 51 (2009), 250-253.

4. Qureshi, SS, EG Rent, M Bhagat, et al: Chyle leak following surgery for abdominal neuroblastoma. J. Pediatr. Surg. 51 (2016), 15571560.

5. Servelle, M: Congenital malformation of the lymphatics of the small intestine. J. Cardiovasc. Surg. (Torino) 32 (1991), 159-165.

6. Huang, Q, ZW Jiang, J. Jiang, et al: Chylous ascites: Treated with total parenteral nutrition and somatostatin. World J. Gastroenterol. 10 (2004), 2588-2591. 
7. Bhatia, C, U Pratap, Z Slavik: Octreotide therapy: A new horizon in treatment of iatrogenic chyloperitoneum. Arch. Dis. Child. 85 (2001), 234-235.

8. Browse, NL, NM Wilson, F Russo, et al: Aetiology and treatment of chylous ascites. Br. J. Surg. 79 (1992), 1145-1150.

9. Yang, C, J Zhang, S Wang, et al: Successful management of chylous ascites with total parenteral nutrition and octreotide in children. Nutr. Hosp. 28 (2013), 2124-2127.

10. Leibovitch, I, Y Mor, J Golomb, et al: The diagnosis and management of postoperative chylous ascites. J. Urol. 167 (2 Pt 1) (2002), 449-457.

11. Kaas, R, LD Rustman, FA Zoetmulder: Chylous ascites after oncological abdominal surgery: Incidence and treatment. Eur. J. Surg. Oncol. 27 (2001), 187-189.

12. Pan, W, SY Cai, HL Luo, et al: The application of nutrition support in conservative treatment of chylous ascites after abdominal surgery. Ther. Clin. Risk Manag. 12 (2016), 607-612.

13. Liu, Y, C Pan, JY Tang, et al: What is the result: Chylous leakage following extensive radical surgery of neuroblastoma. World $\mathbf{J}$. Pediatr. 8 (2012), 151-155.

14. Evans, JG, PE Spiess, AM Kamat, et al: Chylous ascites after post-chemotherapy retroperitoneal lymph node dissection: Review of the $\mathbf{M}$. D. Anderson experience. J. Urol. 176 (4 Pt 1) (2006), 1463-1467.

15. Baniel, J, RS Foster, RG Rowland, et al: Management of chylous ascites after retroperitoneal lymph node dissection for testicular cancer. J. Urol. 150 (5 Pt 1) (1993), 1422-1424.

16. Lam, JC, S Aters, JD Tobias: Initial experience with octreotide in the pediatric population. Am. J. Ther. 8 (2001), 409-415.

17. Zeidan, S, A Delarue, A Rome, et al: Fibrin glue application in the management of refractory chylous ascites in children. J. Pediatr. Gastroenterol. Nutr. 46 (2008), 478-481.

18. Matsufuji, H, T Nishio, R Hosoya: Successful treatment for intractable chylous ascites in a child using a peritoneovenous shunt. Pediatr. Surg. Int. 22 (2006), 471-473.

19. Klein, MD, AI Philippart: Posttraumatic Budd-Chiari syndrome with late reversibility of hepatic venous obstruction. J. Pediatr. Surg. 14 (1979), 661-663.

20. Chang JH, Newkirk J, Carlton G, et al. Generalized lymphangiomatosis with chylous ascites - treatment by peritoneo-venous shunting. $\mathbf{J}$ Pediatr Surg. 1980 Dec;15(6):748-50.

21. Altman, RP, CM Cavett: The retroperitoneal approach for peritoneovenous shunting in infants and small children. J. Pediatr. Surg. 16 (1981), 965-966.
22. Ryan, JA, Jr, MD Smith, CP Page: Treatment of chylous ascites with peritoneo-venous shunt. Am. Surg. 47 (1981), 384-386.

23. Guttman, FM, P Montupet, RS Bloss: Experience with peritoneo venous shunting for congenital chylous ascites in infants and children. J. Pediatr, Surg. 17 (1982), 368-372.

24. Press, OW, NO Press, SD Kaufman: Evaluation and management of chylous ascites. Ann. Intern. Med. 96 (1982), 358-364.

25. Shah, KH, JP Stulc, GR Hoy, et al: Coronary sinus perforation from placement of a LeVeen shunt in a child. Chest 82 (1982), 197-199.

26. Man, DW, L Spitz: The management of chylous ascites in children. J. Pediatr. Surg. 20 (1985), 72-75.

27. Kerr, RS, SJ Powis, JR Ross, et al: Peritoneovenous shunt in the management of paediatric chylous ascites. Br. J. Surg. 72 (1985), 443-444.

28. Salcedo, JR, L Sorkin: Nephritis associated with an infected peritoneovenous LeVeen shunt. J. Pediatr. Gastroenterol. Nutr. 4 (1985), 842-844.

29. Garcia, VF, CG Howell, D Barbot, et al: Small tube peritoneovenous shunting for the management of neonatal intractable ascites. Surg. Gynecol. Obstet. 160 (1985), 273-274.

30. Gillam, GL, KB Stokes, J McLellan, et al: Fulminant hepatic failure with intractable ascites due to an echovirus 11 infection successfully managed with a peritoneo-venous (LeVeen) shunt. J. Pediatr. Gastroenterol. Nutr. 5 (1986), 476-480.

31. Pettitt, BJ: Use of a modified Denver peritoneovenous shunt in a newborn with intractable ascites. J. Pediatr, Surg. 27 (1992), 108-109.

32. Shelat, VG, GJ Pandya, A Shabbir, et al: Post radiation chylous ascites: A case report. Cases J. 2 (2009), 9393.

33. Antao, B, D Croaker, R Squire: Successful management of congenital chyloperitoneum with fibrin glue. J. Pediatr. Surg. 38 (2003), E7-8.

34. Chui, $\mathrm{CH}$ : Mesenteric lymphatic ligation in the prevention of chylous fistulae in abdominal neuroblastoma surgery. Pediatr. Surg. Int. 30 (2014), 1009-1012.

35. Caty, MG, ML Hilfiker, RG Azizkhan, et al: Successful treatment of congenital chylous ascites with a somatostatin analogue. Pediatr. Surg. Int. 11 (1996), 396-397.

36. Olivieri, C, L Nanni, L Masini, et al: Successful management of congenital chylous ascites with early octreotide and total parenteral nutrition in a newborn. BMJ Case Rep. (2012). Sep 25; pii: bcr2012006196. 
37. Roehr, CC, A Jung, H Proquitté, et al: Somatostatin or octreotide as treatment options for chylothorax in young children: A systematic review. Intensive Care Med. 32 (2006), 650-657.

38. Hayashibara, N, T Ogawa, E Tsuji, et al: Efficacy of octreotide against chylothorax following lateral neck dissection for thyroid cancer: A case report. Int. J. Surg. Case Rep. 21 (2016), 107-110.

39. Torrecillas, G, J Medina, ML Diez-Marques: Mechanisms involved in the somatostatin-induced contraction of vascular smooth muscle cells. Peptides. 20 (1999), 929-935.

40. Nussenbaum, B, JH Liu, RJ Sinard: Systematic management of chyle fistula: The Southwestern experience and review of the literature. Otolaryngol. Head Neck Surg. 122 (2000), 31-38.

41. Coskun, A, M Yildirim: Somatostatin in medical management of chyle fistula after neck dissection for papillary thyroid carcinoma. Am. J. Otolaryngol. 31 (2010), 395-396.

42. Nakabayashi, H, H Sagara, N Usukura, et al: Effect of somatostatin on the flow rate and triglyceride levels of thoracic duct lymph in normal and vagotomized dogs. Diabetes 30 (1981), 440-445.

43. Ahn, D, JH Jeon, H Kim, et al: Effect of octreotide injection on postoperative drainage after neck dissection: A preliminary report of a prospective, matched case-control study. Clin. Exp. Otorhinolaryngol. 9 (2016), 173-177.
44. Kuboki, S, H Shimizu, H Yoshidome, et al: Chylous ascites after hepatopancreatobiliary surgery. Br. J. Surg. 100 (2013), 522-527.

45. Jayabose, S, S Kogan, S Berezin, et al: Combined occurrence of chyloperitoneum and chylothorax after surgery and chemotherapy for Wilms' tumor. Cancer 64 (1989), 1790-1795.

46. Pabst, TS, 3rd, KE McIntyre, Jr, JD Schilling, et al: Management of chyloperitoneum after abdominal aortic surgery. Am. J. Surg. 166 (1993), 194-198; discussion 198-199.

47. Sooriakumaran, P, HF McAndrew, EM Kiely, et al: Peritoneovenous shunting is an effective treatment for intractable ascites. Postgrad. Med. J. 81 (2005), 259-261.

48. Rao, SS, S Dundas, CD Holdsworth: Intestinal lymphangiectasia secondary to radiotherapy and chemotherapy. Dig. Dis. Sci. 32 (1987), 939-942.

Luca Pio, MD

Pediatric Surgery Unit

Istituto Giannina Gaslini

Largo G. Gaslini 5, 16147 Genoa, Italy

Tel. +39-010-56362217

Fax +39-010-3075092

Email: lucakeats@hotmail.it 